\title{
MASYARAKAT URBAN, DISKURSUS GENDER DAN PENDIDIKAN KARAKTER: STUDI PERSEPSI DAN EKSPEKTASI PERAN ORANG TUA PEREMPUAN DI JAKARTA
}

\author{
${ }^{1}$ Wuri Handayani \\ ${ }^{2}$ Fauzi Abdillah \\ Universitas Negeri Jakarta \\ ${ }^{1}$ wuri-handayani@unj.ac.id \\ 2abdillah@unj.ac.id
}

\begin{abstract}
This article aims to examine the mother's upbringing in shaping character from a gender perspective. The study from a gender perspective is essential because gender becomes something that cannot be avoided in leading and directing humans to follow gender norms from birth to adulthood. The study was carried out by analyzing primary data, namely in-depth interviews with nine Kindergarten student mothers of TK Labschool in Rawamangun Jakarta. This document study interpreted the thoughts and conveyed them by the informants. The results of this study are positive information about gender discourse, even though they are less cognitively. However, their expectations and perceptions of their children are more on the meaning of a more general scope of character, not based on gendered arenas or not. Without basing on the gender of the child, the necessary characters for the development of an important personality that they prioritize, such as discipline, responsibility, creativity, and freedom of children, determine what they think is suitable for themselves.
\end{abstract}

Keywords: Character Education, Women Parent, Gender Discourse

\begin{abstract}
ABSTRAK
Artikel ini bertujuan untuk mengaji pola asuh Ibu dalam membentuk karakter anaknya ditinjau dari perspektif gender. Studi dari perspektif gender merupakan hal penting sebab sejak seseorang lahir sampai dewasa gender menjadi sesuatu yang tidak bisa dihindarkan dalam menggiring dan mengarahkan manusia untuk mengikuti norma-norma gender. Studi dilaksanakan dengan menganalisis data primer yaitu hasil wawancara mendalam terhadap Sembilan (9) orang Ibu, orangtua siswa TK Labschool di Rawamangun Jakarta, dan studi dokumen ini menginterpretasi pemikiran-pemikiran dan yang disampaikan oleh informan. Hasil dari penelitian ini adalah afeksi informan mengenai diskursus gender cukup positif walau secara kognitif kurang, namun ekspektasi dan persepsi mereka terhadap anak-anak mereka adalah lebih pada pemaknaan skope karakter yang lebih general, tidak mendasarkan pada arena tergenderkan atau tidak. Tanpa mendasarkan pada jenis kelamin anak, karakter mendasar bagi terbangunnya kepribadian yang penting yang mereka utamakan, seperti disiplin, tanggungjawab, kreativitas dan kebebasan anak-anak menentukan yang mereka anggap baik untuk dirinya.
\end{abstract}

Kata Kunci : Pendidikan Karakter, Orang Tua Perempuan, Diskursus Gender 


\section{PENDAHULUAN}

Era pengarusutamaan gender di Indonesia hingga kini sudah berjalan selama tiga dekade jika dihitung dari saat ditetapkannya Inpres nomor 9 tahun 2000 tentang Pengarusutamaan Gender dalam Pembangunan Nasional. Inpres ini menjadi dasar dari diintegrasikannya dimensi gender di dalam pembangunan di seluruh bidang kehidupan. Sudah banyak programprogram pembangunan yang disusun dengan mengintegrasikan gender dalam bentuk program-program pemberdayaan perempuan. Strategi pemberdayaan perempuan yang dilakukan oleh pemerintah mendasarkan pada empat kriteria yaitu meningkatkan akses, partisipasi, manfaat dan kesempatan kontrol pada berbagai program pembangunan bangsa, di berbagai bidang kehidupan, sebagaimana tercantum di dalam kebijakan Inpres tersebut.

Pengintegrasian gender ke dalam program pembangunan selain berupaya memberdayakan perempuan juga untuk menjadikan dasar dari peningkatan kesejahteraan perempuan atau fasilitas yang membantu perempuan menjalani tugas dan tanggungjawabnya, misalkan di tempat-tempat publik ada ruang laktasi, gerbong kereta perempuan dan sebagainya. Pendekatan makro seperti ini telah menghasilkan kemajuan yang dapat dilihat antara lain dari data yang menunjukkan partisipasi perempuan meningkat di bidang pendidikan, birokrasi, politik dan sebagainya. Data yang menginformasikan mengenai tentang capaian pendidikan lakilaki dan perempuan, sebagai berikut : Angka partisipasi perempuan di dalam pasar tenaga kerja adalah laki-laki $84 \%$ diusia produktif sementara perempuan $51 \%$ (Pratiwi, 2017). Pembagian kerja gender ini juga dapat dikaitkan dengan bidang politik. Perempuan yang menduduki jabatan legislatif pusat periode 2014-2019 sebesar $17,32 \%$ (97 orang), turun dari periode
2009-2014 sebanyak 103 orang. (Aritonang, 2014).

\subsection{Tabel Indikator Kesenjangan Gender}

\begin{tabular}{|l|l|l|}
\hline $\begin{array}{r}\text { Kesenjangan } \\
\text { Gender }\end{array}$ & $\begin{array}{r}\text { Perempuan } \\
\text { (\%) }\end{array}$ & $\begin{array}{r}\text { Laki-laki } \\
\text { (\%) }\end{array}$ \\
\hline Presentase \\
Guru: & 96,56 & 3,44 \\
TK & 57,58 & 42,42 \\
SD & 48,40 & 51,60 \\
SMP & 46,94 & 53,06 \\
SMA umum & 32,41 & 67,59 \\
PT & & \\
\hline
\end{tabular}

Sumber: Depdiknas 2007

Dari uraian di atas dapat diasumsikan bahwa di kalangan perempuan cukup meningkat pengetahuan dan pemahaman diskursus gender, sehingga perempuan tidak sedikit yang berpartisipasi di ranah public sehingga secara dinamis berkurang juga waktu dan energinya untuk melaksanakan peran atau tugas-tugas rumahtangga. Dengan demikian dapat diasumsikan adanya suatu pengaruh antara program pemerintah untuk pemberdayaan perempuan dengan jumlah perempuan yang semakin berkualitas. Namun apakah kualitas perempuan yang semakin meningkat ini di dalam menjalankan tugas pengasuhan dan membentuk karakter anakanaknya juga meningkat kualitasnya, sebagai sesuatu yang progresif gender?

Pengaitan pola asuh seorang Ibu dengan diskursus gender sebenarnya suatu hal yang tidak kalah pentingnya dibandingkan dengan penyusunan program-program pemberdayaan tersebut. Ketimpangan gender adalah masalah yang kompleks, perlu penyelesaian berbagai displin ilmu secara simultan. Selain itu struktur permasalahan ketimpangan gender bisa diperkirakan dasarnya pada struktur sosial, artinya hakikat masalah gender adalah struktural. (Ritzer \& Goodman, 2010) Dan penyebab terjadinya permasalahan sosial gender dalam 
masyarakat karena terjadinya sosialisasi nilai-nilai gender, produksi nilai-nilai gender oleh individual dalam interaksinya dengan masyarakat lain dan yang ketiga adalah terjadinya reproduksi nilai-nilai gender oleh pihak-pihak lain misalkan masyarakat dengan penguatan nilai-nilai gender sebagai warisan tradisional atau oleh media massa, opini publik atau oleh mitos-mitos dalam masyarakat.

Dengan demikian keluarga (orang tua) dapat menjadi salah satu sumber sosialisasi nilai-nilai gender.Seorang ibu adalah menjadi model anaknya dalam perkembangan kepribadiannya yang dekat dengan pengaruh /tekanan nilai-nilai gender (Galliano, 2003, hlm. 132). Di dalam pendidikan, gender menjadi ideologi dan skema berpikir anak, yang menjadi dasar dari perkembangan/pembentukan konsep dirinya. Di dalam pendidikan, gender menjadi ideologi dan skema berpikir anak, yang menjadi dasar dari perkembangan/pembentukan konsep dirinya (self-concept) (Galliano, 2003, hlm. 99)

Dari uraian di atas dapat ditemukan urgensi dari dikaitkannya pola asuh anak oleh ibu dengan diskursus gender. Pertanyaan yang muncul kemudian adalah "bagaimana pola asuh Ibu-ibu dalam membentuk karakter anak ditinjau dari perspektif gender". Dalam kehidupan masyarakat dimanapun nampaknya memperhitungkan semua aspek kehidupan, bersama dengan dasar perbedaan gender, yaitu feminine dan maskulin (Galliano, 2003). Gender di dalam aspek pendidikan baik formal, non formal maupun informal tidak dapat dipisahkan dengan masalah gender, sebab proses pendidikan berintikan interaksi.

\section{METODE}

Penelitian ini menggunakan pendekatan penelitian kualitatif dengan menggunakan metode penelitian fenomenologi. Interpretasi dilakukan terhadap temuan penelitian yang didapatkan melalui teknik wawancara mendalam dan studi dokumentasi. Ibu-ibu orang tua siswa TK Labschool sebanyak 9 (Sembilan) orang dilibatkan dalam wawancara mendalam dengan menggunakan pedoman wawancara secara semistruktur dengan pengembangan sesuai dengan kebutuhan lapangan. Data dianalisis melalui interpretasi atau pemaknaan terhadap data hasil wawancara, sebelumnya dengan menyusun sesuai dengan keywords dari teori-teori atau konsep-konsep mengenai pola asuh berbasis progresif gender.

\section{HASIL DAN PEMBAHASAN}

\section{Pola Asuh Ibu dari Masyarakat Urban terhadap Putra dan Putrinya}

Diawali dari penelusuran bagaimana jenis mainan dipilih, para Ibu banyak yang membedakan jenis permainan sesuai gendernya, salah satu informan menyampaikan "tidak mau laki-laki keperempuan-peremuanan" dengan harapan laki-laki memiliki peran gender untuk melindungi perempuan. Ada juga pemilihan mainan berdasarkan tujuan untuk menumbuhkan karakter tertentu seperti sabar, imajinatif, kemandirian, bahagia, peka, aktif, dsb.

Dari perspektif pikiran tubuh, para Ibu ditanyakan mengenai olahraga dan seni apa yang diberikan pada anak, ada yang menjawab hal tersebut sesuai dengan kegemaran anak, ada juga yang sesuai dengan harapan orang tua, misalkan menginginkan anaknya lebih berani, mereka mengarahkannya pada gymnastic, ingin lebih sensitif diarahkan ke balet. Untuk kesenian, hampir semuanya mengarah pada hal yang disukai oleh anak, ada yang diarahkan ke drumband, piano, atau sekadar mendengarkan musik saja. 
Terkait peran laki dan perempuan dilihat dari bacaan, mitos, cerita fiksi dan tontonan televisi memperlihatkan keunikan, misalnya untuk laki-laki:

"tontonan TV langganan tontonan anak-anak seperti cartoon network, baby TV, Nusa dan Hana yang ada agamanya ada belajar sholat, nyanyi sambal menghafal al Quran, ABCD. Biar ada edukatifnya sambal bermain. Tontonan seperti spiderman atau batman saya kasih. Tom and Jerry, tapi porsinya dibagi dan disisipin omar dan Hana. Tetap dipilih, tidak ditiadakan karena takutnya ketinggalan jaman."

Ada pula Ibu ME, wiraswasta berumur 30 tahun yang mempunyai latar pekerjaan ilmu komputer: Mainan: laki-laki mengasah kemampuan -blok2, lego, utk perempuan boneka barbie, yg umur 5 th masig diarahkan tp yg 6 th sdh dibolehkan memilih sendiri, kriterinya sopan-seperti pepapic krn ada tantangan, ipin upin datas, harus tahu kodrat wanita memasak, dan pekerjaan rumah tangga lain, memberi kebebasan utk menetukan berkarier atau tidak, ibu memberi modelling tidak bekerja karena permintaan suami dengan didasari oleh kepatuhan terhadap penafsiran ajaran agama, modelling bahwa menjadi ibu adalah berat, penampilan bagi anak perempuan sama pentingnya dengan prestasi, memberi kebebasan dan fasilitas utk mengambil keputusan bekerja atau tidak, nilai dasar agama, pandangan egaliter laki-laki sm perempuan, pendidikan penting baik bagi ortu maupun anak juga utk menghadapi hidup.

Sementara itu, Ibu EC, 30 th berpendapat bahwa mainan haruslah yang bermanfaat, suami mainan mobil2an utk anak laki2, beda gender beda penanganan (bias gender) anak pr lebih lembut, anak laki2 harus didik utk lebih bertanggung jawab, jangan kolokan, lebih tegas/keras, perempuan juga beratanggung jawab, beda secara fisiologis, karakter shg beda penanganan, ekspektasi tidak bias gender, akhlaq yg utama sbb akan mendorong kepintaran $\mathrm{dlm}$ aspek lainnya misalnya disiplin sholat, modelling bpk utk mbangun anak2 mengerti pekrjaan rt, suami memberi kebebasan untuk bekerja atau tidak, keputusan berkarir melihat dari pengalaman tidk tega meninggalkan anak dan pengalaman orangtua, modelling orangtua, mendidik anak perempuan dengan Tarik ulur.

Di sisi lain, responden Bunda AN, 34 tahun yang seorang arsitek berpendapat bahwa mainan berbie, X-Surprise, Alat Masak dan alat bersih-bersih menarik untuk anak-anak. Lego yang untuk anak perempuan. Untuk menyenangkan anak, reward atas pencapaian, supaya mengenal tugas-tugas perempuan seperti apa (progresif gender) Olahraga gymnastic untuk perempuan yang umur 7 tahun, dan balet untuk umur 5 tahun karena pilihan sendiri. Suami menyerahkan urusan anak kepada istri, terima beres. Istri ikhlas karena suka. Ingin dirumah agar dekat dengan anak-anak. Penampilan tidak lebih penting dari karakter, anak milih sendiri. Pola asuh, wanita punya suara.

Adapun Bunda AR, 39 th, Bunda tidak membelikan mainan, main di alam, karena modelling dari orangtuanya. Suaminya memberi lego, robot-robotan dan rakit-rakitan. Orangtua militer, berharap anak menikmati hidup dialam, agar lebih aktif, peka, dan motoric kasarnya terasah. Suami mengajak bermain pesawat dngan lego, bunda mengajak bermain dialam dengan pesawat kertas, anak dilatih pekerjaan rt, laki-laki harus mandiri dan tanggungjawab. Olahraga sepakbola dan sepeda, suami memberi tontonan superhero, ekspektasi laki-laki banget, bisa melakukan banyak hal, kuat. Penampilan diarahkan casual, pakaian laki-laki, tidak perlu menghabiskan banyak waktu untuk berdandan. Warna baju diberi kbebasan 
untuk memilllih. Tidak pink, karena pink identic dengan perempuan, tidak mengapa pink asalkan sudah dewasa, karena sudah mengerti pribadinya. Wanita dibentuk harus melayani, mengayomi, selalu baik, lembut dan banyak tuntutan dibanding pria. Ibu akan menjadi role model seorang wanita dan harus berani, dan bapak kemaskulinannya yang dilihat (perlindungan). Nilai agaman mengakomodir tugas perempuan. Laki-laki harus menjadi pemimmpin dan harus membantu wanita, tidak berfikir wanita itu lemah. Mendapatkan hal tsb dari pengalaman orangtua. Wanita karir bagus, bisa terlhat hebat diluar, tapi anak butuh orangtua sampai fase tertentu. Suami cukup pada porsi memberi contoh mencuci mobil sendiir, sholat ke masjid.

Bunda Vi, 44 th. Mainan Perempuan mengikuti kakak laki-lakinya, mobilmobilan, bola. Memberi tontonan Disney chanel dan nickelodeon, agar sering menolong dan rasa kepeduliannya tinggi. Yang penting akhlak, pendidikan formal yang kedua. Bekerja diluar dengan izin suami. Melepas pekerjaan dengan ikhlas, mengerti suami sebagai kepala keluarga, rezeki suami rezeki istri. Fitrah istri hanya mengerti buat suami. Patuh karena suami adalah imam. Perempuan bekerja tidaklah salah, keluarga dan anak-anak yang utama. Pekerjaan rumah tangga dikenalman ke anak, tapi tdak diwajibkan, setidaknya mereka tau tugas membantu orang tua.

Bunda Ve, 40 th, S2. Mainan: lakilaki hotweels, lego, karakter hewan, perempuan: berbie LOL, lebih keperempuan-perempuanan. Tidak mau laki-laki keperempuan-perempuan dan sebaliknya. Permainan dan tontonan yang mendidik. Di Youtube banyak yang berbahaya. Laki-laki harus melindungi perempuan. Membacakan cerita nabi-nabi lebih cocok dengan kepercayaan agama dari pada Disney. Agar anak bisa mencontoh dan menerapkan di kehidupan, terhindar dari pembuliyan. Penampilan sesuai dengan keinginan anak. Perempuan lebih bisa berkarya, kemandirian sebagai perempuan untuk mengantisipasi kejadian yang tidak diinginkan. Pekerjaan bukan untuk eksistensi diri tapi untuk keseimbangan, bersosialisasi agar tidak ketinggalan zaman dan aktualisasi diri. Jenis pekerjaan yang fleksible agar lebih banyak waktu dengan anak. Pengalaman ditinggal orang tua pada masa kritis anakanak. Pekerjaan rt diajarkan, prempuan bisa mandiri dalam hal ekonomi. Perhatian ke anak dalam kejadian di lingkungan sekolah harus diperhatikan betul, pembulliyan verbal berasal dari kelalaian perhatian terhadap anak. Anak bisa kehilangan figure orangtua, butuh kedekatan dengan ibunya.

Bunda $\mathrm{Mu}$, Dosen. Mainan, lakilaki lego, berimajinasi, idenya berkembang. Permainan boneka dikenalkan untuk media story telling. Pilih lego karena tes psikologi geometrinya bagus. Penanaman disiplin pada pekerjaan RT: tanggungjawab thd dirinya sendiri, piring kotor, mainan, baju kotor, tempat tidur. Pengenalan buku, mengajak ke toko buku, membacakan buku sebelum tidur, tidak televisi local. Penampilan yang penting nyaman, dan matching, sesuai occasional, warna memilih sendiri, tidak ada beda, ayah juga menggunakan ungu. Konsep mau mencoba pekerjaan RT, bisa sabar dan tanggungjawab. pengalaman orangtua tidak membolehkan mencampuri pekerjaan RT sehingga tidak ingin kejadian tersebut terulang. Suami mau mendengarkan

Bunda Id, 33 th. Mainan: lego, bisa berkreatifitas, berimajinasi. laki-laki bijaksana, Pekerjaan RT tanggungjwab Bersama, pengalaman masa kecil oleh ortu membekas. Perempuan harus bisa cuci mobil, buka baut, bukan hanya nyapu. Pola asuh orangtua menjadi dasar keputusan ibuibu. Pengalaman menjadi dasar keputusan untuk tidak bekerja. Ikhlas tidak bekerja, dan suami membebaskan. Nilai-nilai 
universal mempengaruhi keputusan demokratis suami. Menerapkan nilai-nilai berkata yang baik, Pekerjaan RT dikenalkan kepada anak, lki-laki harus bisa masak. Harapan kepada anak laki-laki menjadi pemimpin keluarga, bijaksana, bisa focus dengan keluarga, harus dibangun dengan kepercayaan. Pemimpin keluarga memahami tugas-tugas istri.

Bunda ES, 31 th. Mainan, perempuan: puzzle, meja rias, bola kecilkecil, masak-masakan biar tau itu mainan untuk perempuan. Ekspektasi, anak happy, mandiri, beradaptasi dengan lingkungan. Paling penting pendidikan. Maunya anak bekerja diluar rumah, balik ke pilihannya kalo suami tidak mengizinkan balik ke kodrat perempuan. Pengalaman diri membuat keputusan untuk tidak bekerja. Rencana pola asuh ke anak laki-laki, jangan sampai manja, penanganan berbeda dengan perempuan, perempuan agak bisa diarahin. Laki-laki harus mandiri, akan menjadi bapak yang bertanggungjawab. Mencari referensi dari baca media sosial, menannyakan ke lingkungan yang mempunyai anak laki-laki. Memberikan asuransi pendidikan untuk persiapan masa depan anak. Pendidikan untuk anak tidak dibedakan. Bekal pendidikan agama, sekolah TK dibiarkan dulu bermain. SD dimasukkan sekolah islam agar ada bekal dasarnya. Di rumah anak diajarkan kata terimakasih, tolong dan maaf. Modelling ajakan sholat, mecuci tangan sebelum makan. Memberi perhatian kepada anak, dengan melihat minat dan bakatnya. Penampilan yang penting bersih dan rapi, dan kualitas pendidikannya lebih penting. Anak laki-laki tidak boleh ada unsur pink baik dimainan maupun pakaian. Memberikan mainan yang menguatkan gender sebagai laki-laki. Laki-laki harapannya punya karakter mandiri, bertanggungjawab dan tidak menyakiti permpuan. Ekspektasi laki-laki mau membantu pekerjaan RT, tidak dipaksakan. Nilai yang akan diturunkan ke anak perempuan dan laki-laki, tenggangrasa, empati, dan mau belajar. Pengalaman yang mendasarinya. Perempuan kodratnya ikhlas, sabar dan ada keterbatasan. Pemberian pendidikan akan ditentukan berdasarkan kualitas dari anak-anaknya tidak memandang laki-laki dan perempuan. Orangtua militer. Suami long distance, suami mempercayakan pola asuh kepada istri.

\section{Menilik Pola Asuh Ibu Masyarakat Urban melalui Perspektif Gender}

Di bawah ini adalah pembahasan pola asuh dari gender norms Rational \& Emotional, Pikiran tubuh, Higher \& lower form, achievement \& sociemotion, dan individuality. Di bawah ini merupakan visualisasi dari pola asuh Ibu yang telah dipaparkan pada bagian sebelumnya. 


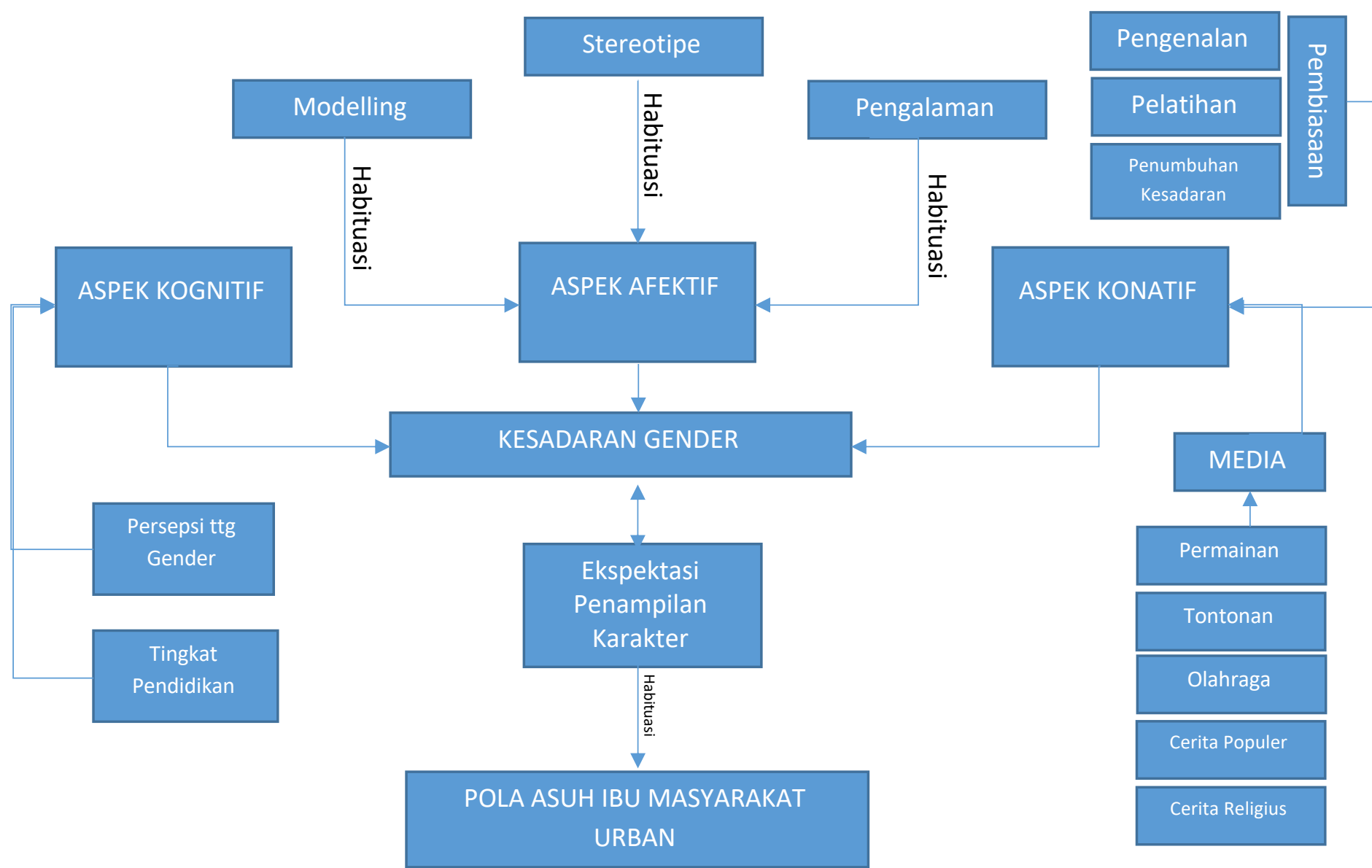

Bagan 1 Pola Asuh Ibu Masyarakat Urban dalam Mendidik Putra-Putrinya di Jakarta 
Dari temuan penelitian tersebut, kita dapat melihat bahwa teori dari Berger \& Luckmann (2013: 14) terkonfirmasi, yang mengatakan bahwa gender merupakan dialektika dari tiga proses yaitu eksternalisasi, obyektivasi dan internalisasi. Hampir sebagian besar mengolah informasi yang ada, dan menyesuaikan dengan kondisi yang mempunyai relevansi dengan lingkungan sosial kulturalnya. Pembagian peran antara suami dan istri pun tertangkap sebagai berbagi peran atas dasar kesepakatan, tidak atas gender semata. Dalam hal itu kita dapat melihat jika seorang suami mempercayakan pola asuh kepada istri, tidak semata-mata lepas tangan, tetapi memang adanya kesempatan, kematangan, dan kesiapan yang lebih banyak daripada pasangannya tersebut.

Kita dapat mengambil pesan dari mainan yang diberikan secara selektif oleh orang tua pada anak. Terdapat ekspektasiekspektasi yang muncul dari apa yang dilakukan oleh orang tua pada anaknya. Sehingga apa yang disampaikan oleh Galliano (2003) bahwa gender akan menjadi ideologi dan skema berpikir anak, yang mendasari perkembangan/pembentukan konsep dirinya (self-concept). Peran orang tua bisa kita cermati dari fenomena-fenomena yang kita simak pada penelitian ini dan penelitian lainnya.

\section{SIMPULAN}

Afeksi informan mengenai diskursus gender cukup positif walau secara kognitif kurang, namun ekspektasi dan persepsi mereka terhadap anak-anak mereka adalah lebih pada pemaknaan scope karakter yang lebih general, tidak mendasarkan pada arena tergenderkan atau tidak. Tanpa mendasarkan pada jenis kelamin anak, karakter mendasar bagi terbangunnya kepribadian yang penting yang mereka utamakan, seperti disiplin, tanggungjawab, kreativitas dan kebebasan anak-anak menentukan yang mereka anggap baik untuk dirinya.

Pemerintah hendaknya menetapkan program sosialisasi diskursus gender sebagai program pendidikan masyarakat. Pendidikan masyarakat ini dimaksudkan untuk memberi pengetahuan dan pemahaman yang lengkap dari berbagai perspektif, sehingga dapat menumbuhkan kesadaran gender di kalangan masyarakat. Pemerintah hendaknya menetapkan secara incremental dan retrospektif mengenai pengarusutamaan gender, dari yang selama ini menggunakan pendekatan makro (institusional) ditambah dengan pendekatan mikro yang lebih bersifat psikologis

\section{DAFTAR PUSTAKA}

Aritonang, D. R. (2014). Ini 97 Perempuan Anggota DPR Periode 2014-2019. Nasional Kompas. Retrieved from https:/www.nasional.kompas.com/

Berger, P. L., \& Luckmann, T. (2013). Tafsir Sosial atas Kenyataan. Risalah tentang Sosiologi Pengetahuan. (H. Basari, Trans.). Jakarta: LP3ES.

Badan Pusat Statistik, tahun 2012". http://bps.go.id/

Depdiknas. (2007). Rangkuman Statistik Persekolahan 2006/2007. Jakarta: Kementrian Pendidikan dan Kebudayan

Galliano, G. (2003). Gender Crossing Boundaries. Canada: Kennes State University.

Pratiwi, A. M. (2017). Rahma Iryanti: Partisipasi Angkatan Kerja Perempuan akan Mempengaruhi Perdagangan 
EKonomi. Jurnal Perempuan. Retrieved from http://jurnalpermpuan.org

Ritzer, G., \& Goodman, D. J. (2010). Teori Sosiologi Modern. (T. W. B. Santoso, Ed.,
Alimandan, Trans.) (Keenam). Jakarta: Kencana Prenada Media Group. 